See Article page 569.

\section{Commentary: Advances in the pursuit of renal protection in TAAA operations}

\author{
Richard J. Shemin, MD
}

Thoracoabdominal resection remains a challenging and complex operation. Protection of the spinal cord and abdominal organs, especially the kidneys, is critical to optimize short- and long-term results. In this issue of the Journal, Kahlberg and colleagues ${ }^{1}$ compare the efficacy of renal perfusion with Custodiol solution versus enriched Ringer's solution for renal protection in patients undergoing open thoracoabdominal aortic aneurysm (TAAA) repair.

Ninety consecutive patients scheduled for elective open TAAA repair were enrolled in a single-center, phase 4, prospective, parallel, randomized, double-blind trial (the CURITIBA Trial). The patients were randomized to renal artery perfusion with $4^{\circ} \mathrm{C}$ Custodiol $(n=45)$ or $4^{\circ} \mathrm{C}$ lactated Ringer's solution $(n=45)$. The incidence of acute kidney injury (AKI) in patients undergoing TAAA open surgery using Custodiol renal perfusion versus an enriched (enriched with $125 \mathrm{mg} / \mathrm{L}$ of methylprednisolone and $12.5 \mathrm{~g} / \mathrm{L}$ of mannitol) Ringer's solution was the primary endpoint.

Ninety patients completed the study (45 patients in each group). The incidence of postoperative AKI was significantly lower in the Custodiol group $(48.9 \%$ vs $75.6 \%$; $P=.02)$. In the multivariable model, only the use of Custodiol solution resulted in protection from the occurrence of any AKI (odds ratio, 230; 95\% confidence interval, $0.086-0.614 ; P=.003)$. At a 1 -year follow-up, serum creatinine levels were not significantly different from preoperative values in either group.

From the Division of Cardiac Surgery, Department of Surgery, Cardiovascular Center at UCLA, David Geffen School of Medicine at UCLA, Los Angeles, Calif.

Disclosures: The author reported no conflicts of interest.

The Journal policy requires editors and reviewers to disclose conflicts of interest and to decline handling or reviewing manuscripts for which they may have a conflict of interest. The editors and reviewers of this article have no conflicts of interest.

Received for publication April 12, 2021; revisions received April 12, 2021; accepted for publication April 13, 2021; available ahead of print April 20, 2021.

Address for reprints: Richard J. Shemin, MD, Robert and Kelly Day Professor and Chief, Division of Cardiac Surgery, 100 UCLA Medical Plaza, Suite 730, Los Angeles, CA 90095 (E-mail: Rshemin@mednet.ucla.edu).

J Thorac Cardiovasc Surg 2023;165:584-5

$0022-5223 / \$ 36.00$

Copyright (c) 2021 by The American Association for Thoracic Surgery

https://doi.org/10.1016/j.jtcvs.2021.04.037

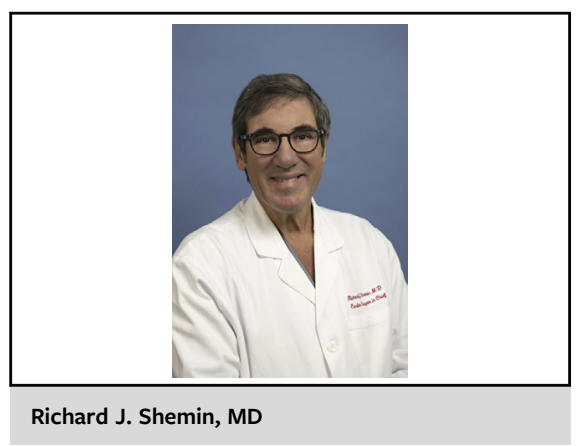

CENTRAL MESSAGE

Evidence from a randomized trial demonstrates safety and efficacy using Custodial solution rather than Ringer's solution to reduce renal insufficiency during thoracoabdominal aortic aneurysm resection.

The authors concluded that the use of Custodiol during open TAAA repair was safe and resulted in significantly lower rates of postoperative AKI compared with Ringer's solution. These findings support the safety and efficacy of Custodiol in this specific setting.

TAAA is a life-threatening disease with an untreated 5-year survival rate ranging around 10\%-20\%. Open surgical repair has proven to be effective in changing the natural history of this disease; however, it remains burdened with considerable perioperative morbidity and mortality rates. Postoperative AKI is associated with an increased risk of cardiovascular events, as well as postoperative and late mortality.

Renal protection methods have been used, such as permissive or active hypothermia lowering the patient body temperature down to $32^{\circ} \mathrm{C}-35^{\circ} \mathrm{C}$ to prevent abdominal organ ischemia. In addition, selective perfusion of the kidneys with a cold crystalloid solution $\left(4^{\circ} \mathrm{C}\right)$, provides a significant reduction in the incidence of AKI.

Histidine-tryptophan-ketoglutarate, or Custodiol HTK solution (Dr Franz-Kohler Chemie, Bensheim, Germany) is a low-potassium preservation solution used for organ transplantation and cardioplegia. Previous observational studies have suggested that renal perfusion with cold Custodiol solutions may prevent AKI during suprarenal aortic cross-clamping. 
This randomized study of Custodiol renal perfusion demonstrates the comparative safety and efficacy, as well as a reduced incidence of postoperative AKI following TAAA repair surgery. Custodial renal perfusion does not prevent renal insufficiency in all cases, however. An optimal perfusion strategy for the Custodial solution may further enhance efficacy. Thus, further strategies with alternate solutions must continue to be investigated to further improve renal preservation.

\section{Reference}

1. Kahlberg A, Tshomba Y, Baccellieri D, Bertoglio L, Rinaldi E, Ardita V, et al Renal perfusion with histidine-tryptophan-ketoglutarate compared with Ringer's solution in patients undergoing thoracoabdominal aortic open repair. $J$ Thorac Cardiovasc Surg. 2023;165:569-79.e5. 